\title{
Study on streamflow response to land use change over the upper reaches of Zhanghe Reservoir in the Yangtze River basin
}

\author{
Yuqi Chen ${ }^{1}$, Jun Niư ${ }^{1,2,3^{*}} \mathbb{D}$, Yuqing Sun ${ }^{1,2}$, Qi Liu' ${ }^{1,2}$, Sien $\mathrm{Li}^{1,2}$, Peng $\mathrm{Li}^{4}$, Liqun Sun ${ }^{3}$ and Qinglan $\mathrm{Li}^{3}$
}

\begin{abstract}
The Zhanghe Reservoir in Yangtze River basin plays a key role in fulfilling the crop water requirements of the irrigation area in its downstream region. This study employs the SWAT (Soil and Water Assessment Tool) model to simulate the variations of Zhanghe Reservoir inflow. The model performed well at monthly timescale, with the values of both NSE and $R^{2}$ above 0.7. The land use distribution and the structure changes in 1990, 2000, and 2015 are employed to study the reservoir inflow responses to the land use changes in the contributed basin area. In the historical period (1990-2000), the streamflow was decreased by $0.4 \%$, accompanied by the reductions of farmland and grassland area, and the increase of forestry area. The land use scenarios are further designed for considering possible future land use alterations. The low flow responses to the completely forestry cover for the basin is more obvious to the completely grassland cover. Accordingly, the further afforestation may aggravate the drought situation due to the low flow reduction. In addition, the high flow responses are reversed to these two land cover situations. The obtained results are useful for designing future sustainable development strategies for the region.
\end{abstract}

Keywords: Streamflow, Forestry, Farmland, Land use change, Zhanghe reservoir

\section{Introduction}

The land use/cover in a river basin is dynamically changing with the evolutions of regional population, climate changes, and local policies. In the meanwhile, the changes of land use are also a contributing factor in the regional or global environmental changes. Therefore, the runoff responses to land use changes both the regional water flow conditions and available amount of water resources. Many studies have reported that the land use plays an important role in streamflow variations (Han DD 2018). With a decrease of vegetation cover, in case the soil infiltration characteristics are not be changed, the base flow will be increased (Bruijnzeel 2004). However, this situation is not favorable to regional sustainability development, as the soil texture will be compacted. Bonell et al.

\footnotetext{
*Correspondence: niuj@cau.edu.cn

${ }^{1}$ Center for Agricultural Water Research in China, China Agricultural University, Beijing 100083, China

Full list of author information is available at the end of the article
}

(2010) indicate that it will induce the decrease of infiltrated water, and affect groundwater recharge. Bradshaw et al. (2007) studied the relationship between floods and forest area changes, and found afforestation is helpful to reduce the frequency and the severity of floods. Guo et al. (2008) studied the deforestation of natural forest over the Poyang Lake in Yangtze River basin, the increase of monthly and seasonal streamflow is observed during the flooding season, and the decrease of them is found during the dry season. Li et al. (2007) pointed out that the converting of farmland to forest and grassland made the Daqing River to have a decrease trend of streamflow. Hao et al. (2015) analyzed the spatial-temporal transfer characteristics of land use, and used the scenarios of land use changes to evaluate the streamflow changing trend. Many researches aimed to understand the underlying reasons and ways of land use changes, and summarize the hydro-ecology system responses to land use changes (Gutman et al. 2004; Gashaw et al. 2018; Sriwongsitanon 
and Taesombat 2011; Serpa et al. 2015; Zhang et al. 2018; Han 2018). The obtained results are favorable to regional ecosystem protection and useful to the flood and drought prevention and mitigation.

There are mainly three approaches for studying streamflow responses to land use changes, namely experiment study, statistical analysis, and hydrologic modeling (Li et al. 2016). Experiment study is based on actual operation experiments and the analysis is performed on the experimental results. However, it requires the observations for a very long period. Statistical analysis is a comprehensive description using some mathematical methods of statistics, which needs enough hydrological data to support it. The hydrological model method is based on the conservation of water and energy in nature, taking into account the spatial characteristics, and better combining the actual situation. Based on geospatial data, combined with land use and ecological construction, it can simulate complex hydrological cycle processes and better reflect the actual situation for a long time period. The first two approaches are difficult to describe the spatial responses of runoff to land use change, and the hydrological modeling could consider natural homogeneity and is capable to simulate the complex water cycles.

The distributed hydrological model-Soil and Water Assessment Tool (SWAT)-was employed in this study. The SWAT model was developed in 1994 by the Doctor Jeff Arnold from Agricultural Research Service (USDA) (Ficklin et al. 2012). The SWAT model was widely applied with different spatial-temporal scales in different watersheds (Park et al. 2011; Govender and Everson 2005). Through the applications, the SWAT model has been demonstrated to be applicable and have high capability to study various issues on runoff (Bouraoui et al. 2005), sediment (Dechmi and Skhiri 2013), water quality (Dechmi and Skhiri 2013), land use (Hernandez et al. 2000), among other aspects. With considering the effective physical mechanism, SWAT model can simulate the impacts of various land use types on the hydrological processes of the basin through incorporating land use data obtained from remote sensing (Xu and Cheng 2010).

In a long-term period, the Zhanghe Reservoir plays a key role in fulfilling the irrigation water requirements for the agricultural land area in Jinzhou, Yichang, and Jingmen cities, with the total area about 2.6 million $\mathrm{mu}$, which is the key water sources of Zhanghe irrigation district. The major function of the Zhanghe Reservoir is irrigation as the statistical data indicates that the total water supply for the Zhanghe irrigation district for the past 6 decades is about 19.8 billion $\mathrm{m}^{3}$ (Fang 2004). In addition, the reservoir has other functions, including flood control, shipping, hydro-power generation, domestic water supply, and touristy (Yang and Lin 1997).
According to the analysis of historical hydrologic records, there are 5 extreme drought events in recent years, which are year 2005, 2011, 2012, 2013, and 2014. The reported study (Niu and Sivakumar 2014) indicates that the possible land use changes may have more obvious impacts on low flow; therefore, the understanding the streamflow responses (especially the extreme flow) to land use changes is necessary for the region. The study on the streamflow responses to land use changes is an important step for the forecasting of the reservoir inflow, and will be useful to promote the sustainable development of socialeconomic development of the Zhanghe agricultural irrigation district.

The applications of SWAT model have been demonstrated in many studies. This study employs the SWAT model to simulate the inflow processes under the land use changes over the control area of Zhanghe Reservoir. To this end, we select both NCEP (National Centers for Environmental Prediction) and CMADS (China Assimilation Driving Datasets for the SWAT) datasets for the meteorological forgings of the model simulation. The streamflow responses to land use changes are performed in 1990, 2000, and 2015, respectively, and the deigned scenarios of land use changes are also examined.

The variations of reservoir inflow are important issues to the downstream irrigation district of Zhanghe Reservoir. We need to assess the possible changes in the studied area. Among it, the land use change is an important aspect. The purpose of this study is to examine the streamflow response to land use changes for both historical period and future period (reflected by possible land use scenarios). The remaining parts of the paper are organized as follows. The study area, methods and data adopted in the present study are first presented in "Study area" and "Methods" sections, respectively. The reservoir inflow processes are simulated, and the streamflow responses to land use changes are examined and discussed in "Results" sections. The conclusions are given in "Discussions" sections.

\section{Study area}

The Zhanghe River basin (see Fig. 1) originates Sanjing Village, Nanzhang County in south part of Jinshan Mountain of the Hubei Province, which is the eastern tributary of Juzhang River, located in the $111-112^{\circ} \mathrm{E}$ and $30-32^{\circ} \mathrm{N}$. The total main stream is about $202 \mathrm{~km}$, from southeast to northwest tilted, with the elevation in the range of 42-1400 $\mathrm{m}$ (Fang 2004) and the total basin area $2980 \mathrm{~km}^{2}$. Zhanghe Reservoir is located in Zhanghe Town, Jingmen City, Hubei Province, China. The reservoir inflow from the Zhanghe River Basin is about 92.4\% of the total inflow according to the records provided by Hubei Zhanghe Project Administration Bureau for the 


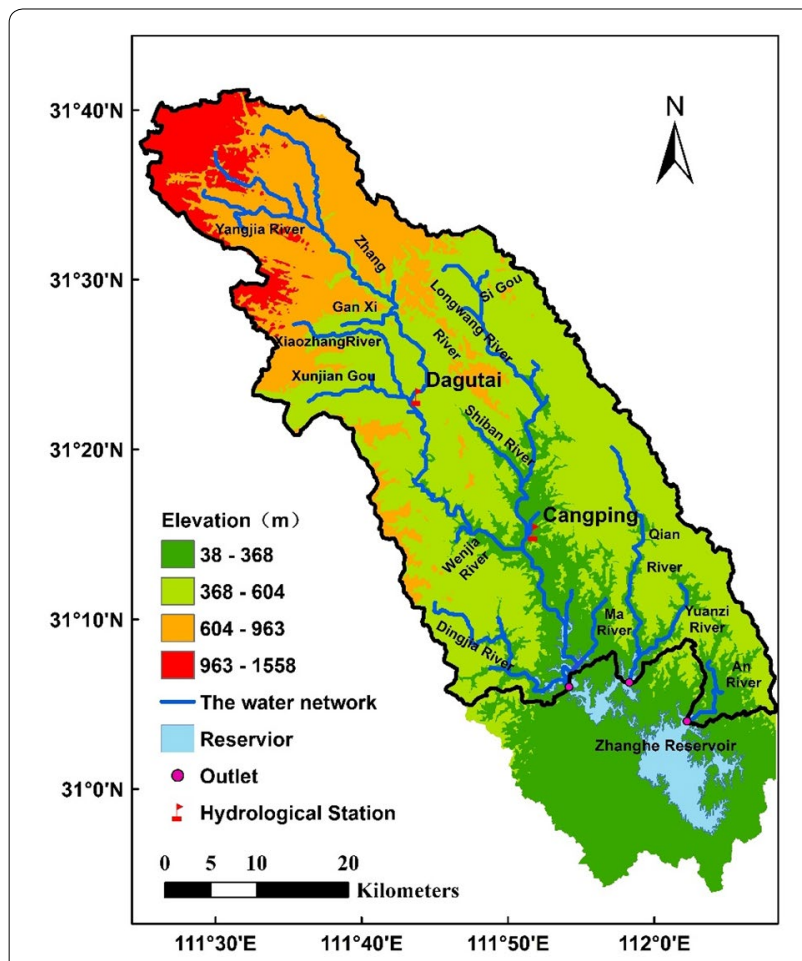

Fig. 1 The upper reaches of Zhanghe Reservoir in Yangtze River basin, and its river network, the gauging stations, and basin outlets

period of 2002-2011. The basin belongs to the subtropical monsoon climate in the middle reaches of the Yangtze River. The internal temperature difference is very large within a year. The most hot seasons are July and August, and the temperature can reach $40.9{ }^{\circ} \mathrm{C}$. The most cold seasons are January and February, and the temperature can reach $-19{ }^{\circ} \mathrm{C}$. Annual evaporation is about $700-$ $1000 \mathrm{~m}$, with monthly maximum $150 \mathrm{~mm}$ and monthly minimum $16.5 \mathrm{~mm}$. Annul long-term precipitation is about $987.4 \mathrm{~mm}$. There are large precipitation variabilities in both seasonal and spatial scales.

The Zhanghe Reservoir was constructed in 1958, and completed in the April of 1966 . The reservoir capacity is about 2.13 billion $\mathrm{m}^{3}$, and the control catchment area is $2212 \mathrm{~km}^{2}$. There are several inflow tributaries and the corresponding outlets. The dominant inflow tributary is Zhang River, with two hydrological stations, namely Dagutai (the control area $727 \mathrm{~km}^{2}$ ) and Cangping (the control area $402 \mathrm{~km}^{2}$ ), located in this tributary. The Arcgis software was employed to delineate the boundary of study area based on Digital Elevation Data. We then collected the land use raster data and soil raster data of Hubei Province, and extracted them for the study area. The classification standard of land use types is based on the National Remote Sensing Monitoring Land Use/ cover classification system. Soil classification is based on

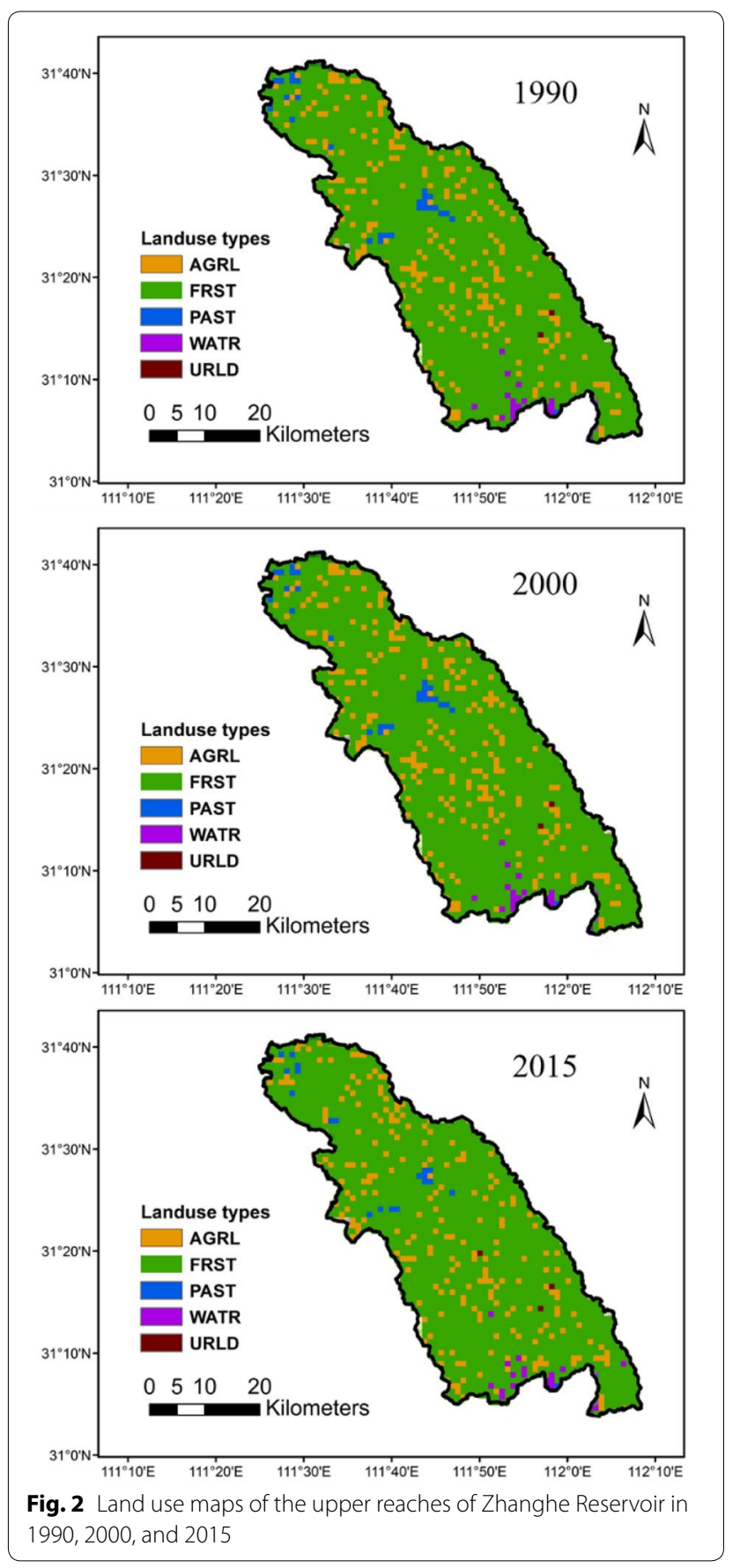

HWSD database. The Land use/land cover is provided by the Resource and Environment Data Cloud Platform. There are mainly five vegetation types over the area (see Fig. 2). Among it, more than $80 \%$ of the total area is covered by forestry. Soil types are provided by the Harmonized World Soil Database 1.1. There are 9 soil types in the region (see Fig. 3). The long-term annual average precipitation for the contributed area in Fig. 1 is about 


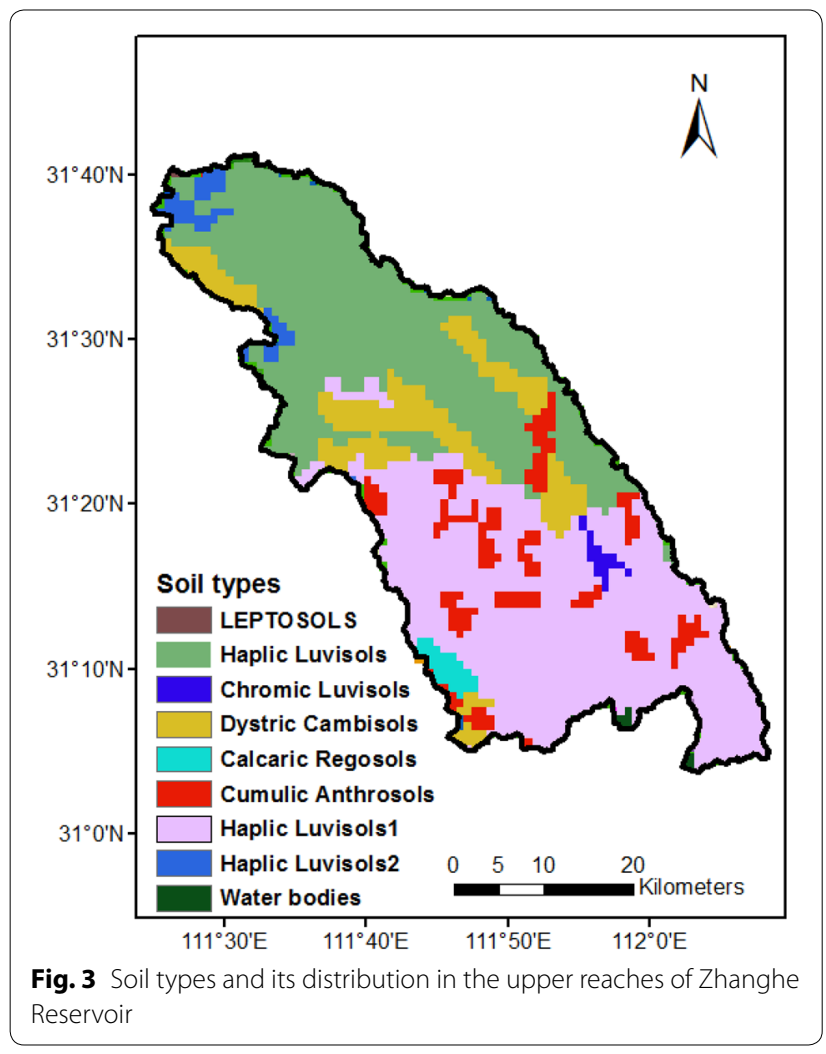

$1088 \mathrm{~mm}$ for the period of 2002-2011. The Zhanghe Reservoir serves as the incoming water source for the Zhanghe agricultural irrigation district (the largest irrigation district in Hubei Province). The annual agricultural water supply is 317.98 million $\mathrm{m}^{3}$ for the period of 19632016, the annual industry water supply is 37.97 million $\mathrm{m}^{3}$ for the period of 1975-2016, the annual domestic water supply is 26.24 million $\mathrm{m}^{3}$ for the period of 1988 2016 , and the annual urban ecological water supply is about 14.83 million $\mathrm{m}^{3}$ for the period of 2007-2016.

\section{Methods}

\section{Model description}

The distributed hydrological model-SWAT (Soil and Water Assessment Tool) (Arnold et al. 1998)-was employed in this study to simulate the hydrologic processes. Based on the sufficient hydrological physical mechanisms, SWAT model can effectively predict the runoff under the conditions of different soil types, land use types, weather situation, and the disturbance of human activities (Gikas et al. 2006). In the application of SWAT model, the catchment was separated into multiple sub-basins based on the digital elevation model (DEM) (see Fig. 4), and the study area was divided into 56 subbasins. Then, the sub-basin was further divided into hydrologic response unit (HRU) in terms of the terrain,

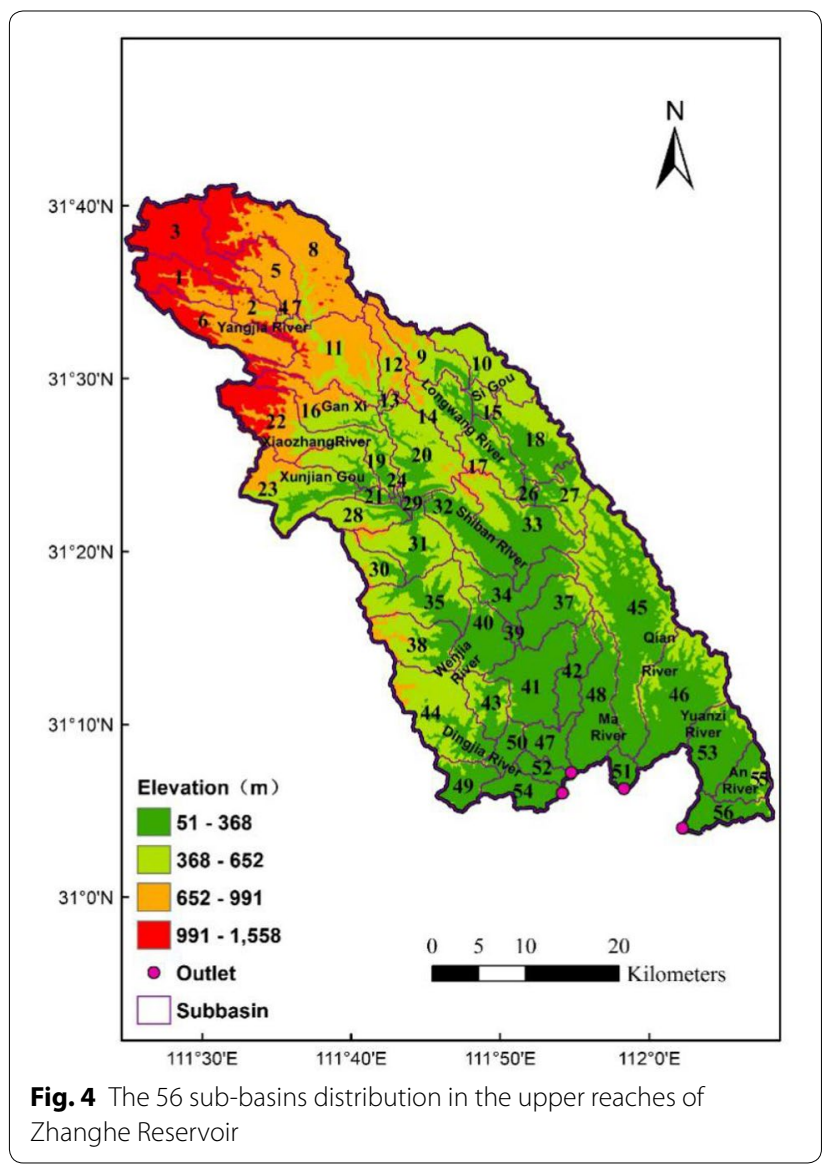

land use and soil types. HRU is the combination of smallest simulation unit which has the similar land use and soil type (Meng et al. 2015), and there are 377 hydrologic response units being generated in this study area.

In case there is a missing value of rainfall data, the weather generator can be used accordingly. The generation of precipitation uses the model developed by Nicks (1974) which can not only produce daily precipitation data due to the lack of the observed data but also fill the missing value of actual records. The calculation of runoff employs SCS curve number (USDA-SCS, 1972) procedure, in which the main parameter is $\mathrm{CN}$ value. SCS curve describes the relationship between precipitation and runoff, which synthesizes the previous moisture conditions of soil, gradient, soil type, land use situation and other factors together and indirectly reflects the effects of human activities on runoff (Neitsch et al. 2002). For the routing of main channel, the flow moving from upstream to downstream is partly evaporated and lost by riverbed transport, while some is utilized in different ways, such as agricultural irrigation, industrial water and urban and rural water supply, and the remain is the discharge at the outlet. SWAT model only considers non-pressure 
flow, with selecting Manning's equation to calculate the speed of confluence. With the information of channel slope, length, sectional area and so forth, the Muskingum method proposed by Williams (1969) is adopted to calculate the processes of confluence and the flow dynamics at the watershed outlet.

\section{Data input and model setup}

The establishment of the model requires a newly built database to support the operation of the SWAT model. First, DEM is used to generate the water system and delineate the basin boundary. The data applied in this study are with the spatial resolution of $90 \mathrm{~m}$. To analyze the change of land use, we selected three land use maps of $1000 \mathrm{~m}$ spatial revolution which were in different periods and those data are obtained from environmental data cloud platform of the Chinese Academy of Sciences. The required data, including soil and vegetation information, meteorological forgings, are listed in Table 1. Hydrological response unit is defined as the smallest hydrological calculation unit in SWAT model, which is composed of unique land use type and soil type. For HRU classification, the different regions with the same combination in sub-watershed are divided into the same type of HRU, and the purpose of reclassification is to merge the same HRUs. The number of HRUs directly affects the running speed of the model. The land use types and soil types need to be reclassified to reduce the amount of HRU that finally generated in model. The calculating of several soil parameters is by means of Soil-Plant-Air-Water (SPAW) software when we prepared soil data. SPAW system is used to calculate paddy field and pond models and analyze soil moisture characteristics. It is an auxiliary tool of Arc-SWAT soil database. In the database that supports SWAT model, soil data need physical parameters of soil, such as soil moisture density, effective water-holding capacity of soil layer, and saturated hydraulic conductivity coefficient, which need to be calculated using the software of SPAW. The meteorological data include daily precipitation, maximum temperature, minimum temperature, wind speed, relative humidity, and solar radiation. NCEP meteorological data were download from NCAR/ UCAR RDA official webpage (http://rda.ucar.edu/). The spatial resolution is one degree by one degree, and the temporal resolution is daily. The time length is 20012012. CMADS datasets are from Cold and dry area scientific data center. The spatial range of the data is $0^{\circ} \mathrm{N}-65^{\circ}$ $\mathrm{N}, 60^{\circ} \mathrm{E}-160^{\circ} \mathrm{E}$, and the resolution is $0.25^{\circ}$, and the time length is for the period of 2008-2016. The dataset can provide daily average temperature, daily maximum/minimum temperature, daily accumulated 24-h precipitation, daily average solar radiation, daily average air pressure, daily specific humidity, daily relative humidity, and daily average wind speed.

\section{Sensitivity analysis, model calibration, and validation} SWAT-CUP (SWAT Calibration and Uncertainty Programs) is a computer program developed by Abbaspour et al. (2007), which can perform parameter sensitivity analysis, calibration, validation and uncertainty analysis about SWAT model. And the five optimization methods contained in SWAT-CUP are GLUE, Para Sol, SUFI-2, MCMC, and PSO. Among them, the SUFI-2 has been widely used by researchers and this study employs SUFI-2 to complete sensitivity analysis, calibration, and validation. SUFI-2 is a procedure adopting gradient search and calculating with parameters obtained through Latin hypercube sampling (Wei et al. 2012; Mehan et al. 2017). Based on the relevant literature review, 16 parameters (in Table 2) were selected for sensitivity analysis. Sensitivity analysis is mainly controlled by two indicators. The $\mathrm{p}$ value determines the significance of sensitivity, and the closer the $\mathrm{p}$ value is to 0 , the more significant it is. T-stat indicates the degree of sensitivity, and the greater the absolute value is, the more sensitive it is ( $\mathrm{Li}$ et al. 2015). With the performance of the sensitivity analysis, there

Table 1 Geographical information, climate forcing, and streamflow records used for model simulation, calibration, and validation

\begin{tabular}{|c|c|c|}
\hline Data type & Date description & Source \\
\hline Digital elevation model & $90 \mathrm{~m} \times 90 \mathrm{~m}$ resolution & Geographical Information Monitoring Cloud Platform \\
\hline Land use map & 1:100,000 scale, 5 basic land use types, 1990, 2000, 2015 & Resource and Environment Data Cloud Platform \\
\hline Soil map & $1: 1,000,000$ scale, 8 soil types & Harmonized World Soil Database1.1 \\
\hline Soil characteristics & $\begin{array}{l}\text { Properties were quantified based on measurements or esti- } \\
\text { mated using SPAW model and EXCEL }\end{array}$ & China Soil Database \\
\hline Meteorological data & $\begin{array}{l}\text { Daily precipitation, temperature, relative humidity, wind } \\
\text { speed, Solar (1993-2013) }\end{array}$ & $\begin{array}{l}\text { NCEP (National Centers for Environmental Prediction) and } \\
\text { CMADS (China Meteorological Assimilation Driving Data- } \\
\text { sets for the SWAT model Version 1.1) }\end{array}$ \\
\hline Streamflow data & Daily streamflow of hydrological station (2001-2012) & Zhanghe engineering administration bureau \\
\hline
\end{tabular}


Table 2 Parameters and parameter range used in sensitivity analysis for streamflow simulation

\begin{tabular}{|c|c|c|c|}
\hline Parameter & Description & Range & Process \\
\hline$r_{-} \mathrm{CN} 2$ & SCS runoff curve number for moisture condition II & -.3 to 0.3 & Streamflow \\
\hline$v_{-}$ALPHA_BF & Base flow alpha factor (days) & 0 to 1 & Groundwater \\
\hline$v_{-}$GW_DELAY & Groundwater delay times (days) & 0 to 500 & Groundwater \\
\hline$v_{-}$GWQMN & $\begin{array}{l}\text { Threshold depth of water in the shallow aquifer required for return flow to } \\
\operatorname{occur}(\mathrm{mm})\end{array}$ & 0 to 5000 & Groundwater \\
\hline$V_{-}$GW_REVAP & Groundwater "revap" coefficient & 0.02 to 0.2 & Groundwater \\
\hline$v_{-}$SFTMP & Snowfall temperature $\left({ }^{\circ} \mathrm{C}\right)$ & -5 to 5 & Snow \\
\hline$v_{-}$TIMP & Snow pack temperature $\left({ }^{\circ} \mathrm{C}\right)$ & 0 to 1 & Snow \\
\hline$v_{-}$SURLAG & Surface runoff lag time (days) & 0.05 to 24 & Streamflow \\
\hline$v_{-}$ESCO & Soil evaporation compensation factor & 0 to 1 & Evaporation \\
\hline$v_{-} \mathrm{CH}_{-} \mathrm{N} 2$ & Manning coefficient for channel & -0.01 to 0.3 & Channel \\
\hline$v_{-} \mathrm{CH}_{-} \mathrm{K} 2$ & Effective hydraulic conductivity in main channel alluvium (mm/h) & -0.01 to 500 & Channel \\
\hline a_RCHRG_DP & Groundwater recharge to the deep aquifer & 0 to 1 & Groundwater \\
\hline$r_{-}$ALPHA_BNK & Baseflow alpha factor for bank storage & 0 to 1 & Channel \\
\hline$r_{-} \mathrm{SOL} \_\mathrm{AWC}$ & Available water capacity of the soil layer(mm/mm) & -0.3 to 0.3 & Soil \\
\hline$r_{-} \mathrm{SOL}_{-} \mathrm{BD}$ & Soil conductivity(mm/h) & -0.3 to 0.3 & Soil \\
\hline$r_{-} \mathrm{SOL}_{-} \mathrm{K}$ & Saturated hydraulic conductivity of first layer (mm/h) & -0.3 to 0.3 & Soil \\
\hline
\end{tabular}

$r_{\_}$: parameter value is multiplied by $(1+$ a given value $) ; v_{\_}:$parameter value is replaced by given value; $a_{-}$: parameter value is added a given value

Table 3 The sensitive parameters and their characteristic values in the modeling

\begin{tabular}{llcc}
\hline Parameters & $\boldsymbol{p}$ value & T-stat & Best value \\
\hline r_SOL_BD & 0.00 & -8.54 & 0.26 \\
v_CH_N2 & 0.07 & -1.84 & 0.25 \\
v_CH_K2 & 0.11 & -1.60 & 9.76 \\
r_SOL_AWC & 0.11 & -1.59 & -0.21 \\
V_SURLAG & 0.12 & 1.56 & 18.05 \\
r_SOL_K & 0.15 & -1.46 & -0.05 \\
v_GW_REVAP & 0.15 & 1.45 & 0.094 \\
r_CN2 & 0.33 & -0.97 & -0.07 \\
v_SFTMP & 0.39 & 0.86 & -4.19 \\
v_ALPHA_BF & 0.46 & -0.75 & 0.85
\end{tabular}

$p$ value indicates the significance of the $t$ value: the smaller the $p$ value, the less chance of a parameter being accidentally assigned as sensitive. $T$-stat indicates parameter sensitivity: the large the $t$-stat, the more sensitive the parameter

are 10 parameters being regarded as the relatively sensitive parameters in this study (Table 3 ).

The calibration is done by contrasting simulated streamflow with the observed data, then adjusting the value of parameters to keep the error within reasonable range, which can make the structure and parameter values of model more suitable with the actual condition of study area. There are two indices being used to quantify the suitability of model, which are coefficients of determination $\left(R^{2}\right)$ and Nash-Sutcliffe (NSE) (Nash and Sutcliffe 1970), respectively.

\section{The design of land use scenarios}

To better provide strategies for sustainable development of regional social-economy and environment protection, the different land use scenarios are designed for studying the possible streamflow response. Normal scenario is compared to 2000. Among them, Scenario A assumes that the total catchment area is completely covered by grassland, and the land is fully occupied by forestry in Scenario B. The two scenarios are extreme situations for examining the model performance on the vegetation cover change in the studied area, and Scenario B is also related to afforestation as the forestry is the dominate vegetation cover for the region. According to the past land use map in Fig. 2, the land use changes concentrate in the area changes of forestry, farmland, and urbanization area, which is similar with the upper Du watershed (Yan et al. 2013). In Scenario C, a part of forestry is converted to farmland, and Scenario D is the farmland partly transferred into forestry. Scenarios C and D are related to the expanding or reducing the area of the farmland. Meanwhile, the Scenario E considers urbanization, as the urbanization is possible situation with the regional social-economy development. Scenario $C$ is designed because the forest area in the study area is the largest, so the forest land reduction is considered. Scenario D is designed to respond to the policy of returning farmland to forests. Considering that the current urbanization construction is also very important, scenario $E$ is designed to increase the construction land area with an assumed 
changing range. The land use/cover percentages of each scenario are shown in Fig. 5.

\section{Results}

\section{Historical streamflow simulation and validation}

In this study, the observed streamflow in Dagutai and Cangping gauging stations during period 2001-2012 was obtained from the Zhanghe engineering administration bureau. The 2001 year was set as the warm-up period, while the period from 2002 to 2007 and the period from 2008 to 2012 were chosen to be the calibration and validation period, respectively. In validation period, CMADS (The China Assimilation Driving Datasets for the SWAT) also was applied to simulate the processes of streamflow. The comparison between the simulated streamflow and observations of gauging stations is shown in Fig. 6, which describes that the variations of simulated streamflow processes with the CMADS are closer to the actual streamflow processes, thereby validating the better applicability of CMADS for SWAT model for this region. The observed differences are partly due to the limited forcing meteorological data for the studied region. Certainly, the effectiveness of model simulation, regarding to the model structure and parameterizations, also affects the simulation accuracy. The detail calibrated and validated results are listed in Table 4. The fitness of SWAT model in study area can be quantified, as the value of $R^{2}$ was within the range of 0.71 to 0.84 , and NSE was above 0.7 at each gauging station, especially for the simulated results with the CMADS in Cangping gauging station.

\section{Streamflow responses to historical land use changes}

The land use changes for the historical period are examined in terms of both land use area and its structure. Figure 7 shows that there are basically 5 land cover types, based on the land use data in 1990, 2000, and 2015 . AGRL stands for farmland; FRST for forest land; PAST for grassland; WATR for water area; and URLD for construction land. The main land cover types are forestry, farmland, and grassland. Among it, the grassland covers about $85 \%$ of the total area. For the three time positions, the forestry was reduced a little bit in the first time stage, and increased in the second time stage. The farmland is slightly increased and then decreased. The water and urban area are quite small, and there basically no changes during the period of 1990-2000. However, for the period of $2000-2015$, the urban area is increased by $33 \%$.

The land use transfer matrix is established in Table 5, for analyzing the historical changes of land use structure, which shows the dynamic transfer information for different time periods. The procedures of the establishment of land use transfer matrix include (1) to prepare the land use status map (SHP format) in 1990 and 2015 with ArcGIS software, in which each map attribute table should

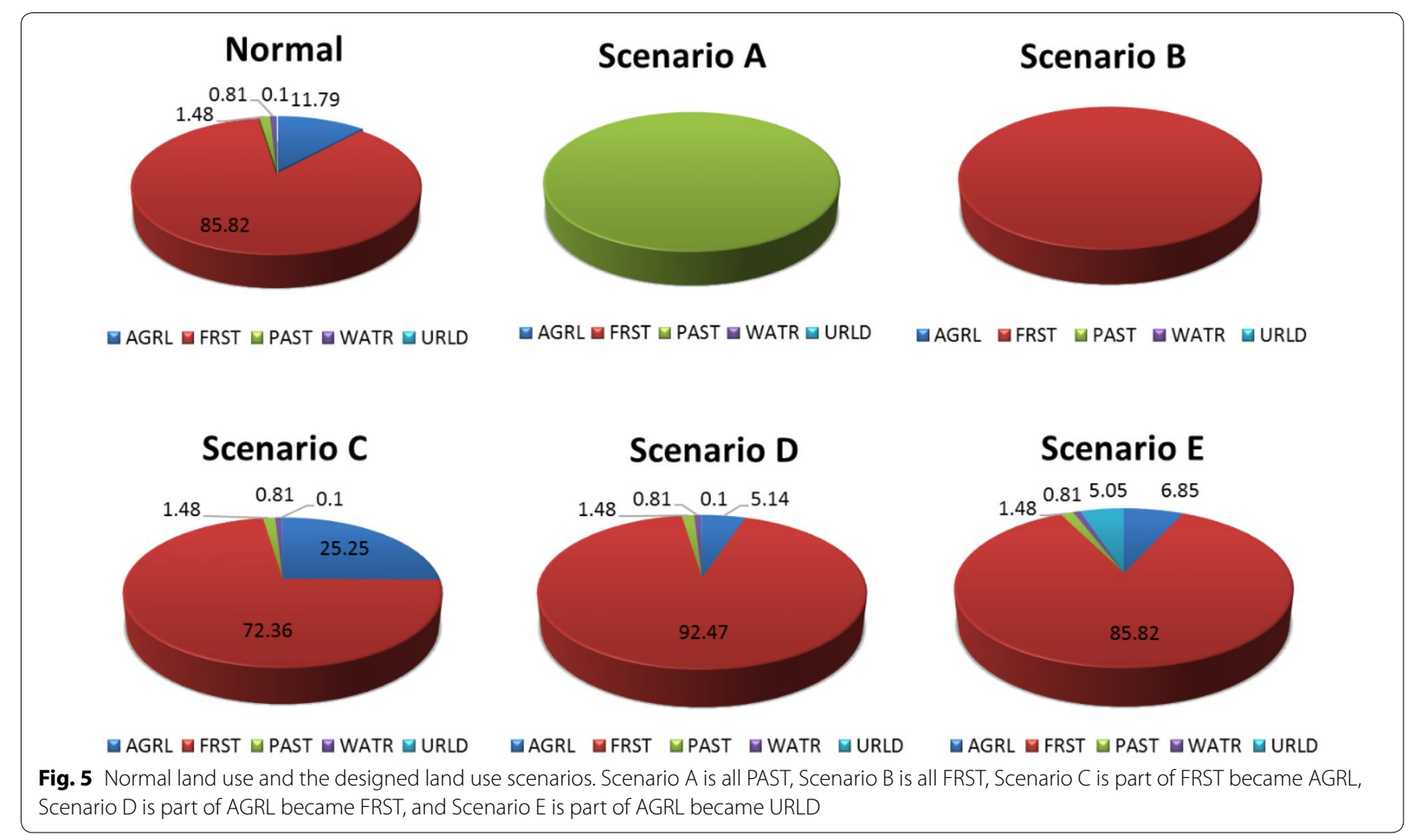




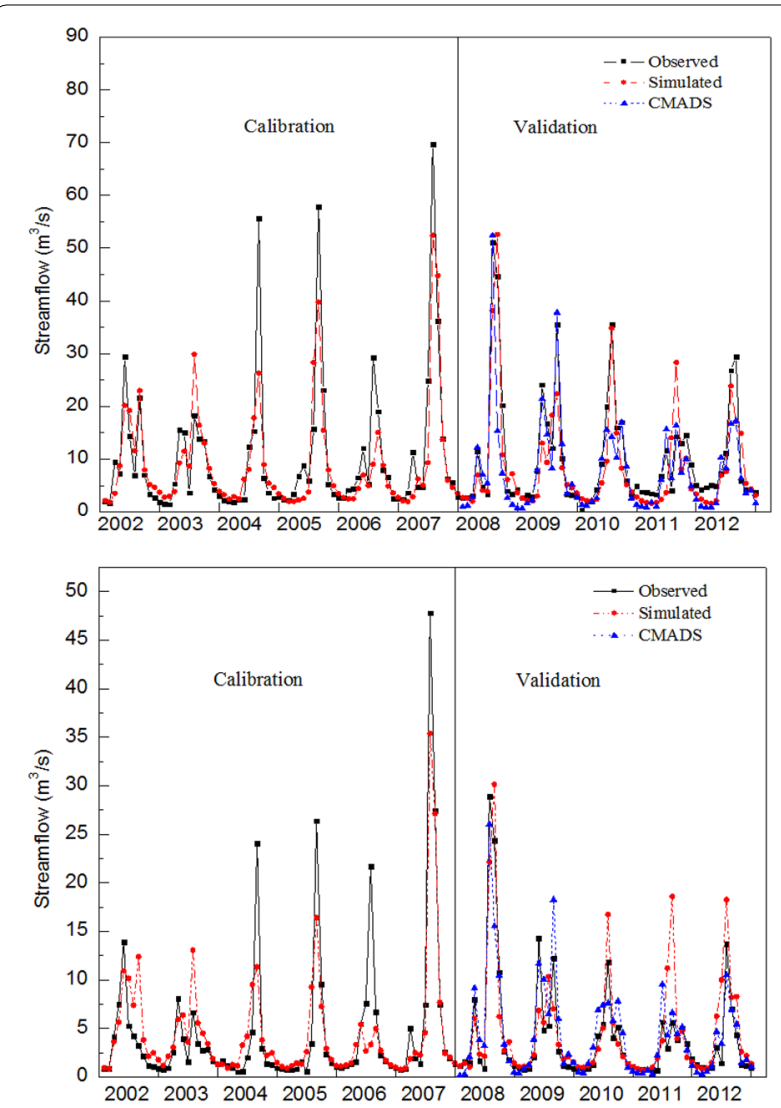

Fig. 6 The simulations and observations of the monthly streamflow at Dagutai (upper one) and Cangping (lower one) gauging stations have a field representing the land use type; (2) to use the solver tool in ArcGIS software to fuse the data; (3) the area is calculated and the attribute table is derived; and (4) to load the property sheet in Excel, and calculate the matrix automatically. The mutual transfer ratio between farmland and grassland is relative higher, and the total percentage of grassland is decreased. More farmland area was converted to the forestry, and the percentage reaches to $56 \%$.

As both climate change and land use/cover change will affect the regional runoff production, we studied the streamflow responses to the land use changes with the fixed meteorological forgings for the studied area. Among the $1088 \mathrm{~mm}$ (the long-term annual average for the period of 2002-2011) precipitation for the contributed area in Fig. 1, the annual average evapotranspiration and annual average runoff are about $530 \mathrm{~mm}$ and $392 \mathrm{~mm}$, respectively. Then, we simulate the streamflow using calibrated model with the different land use data. The streamflow is reduced due to the changes from forestry to farmland from the land use situation in 1990 to 2000. For the land use situation from 2000 to 2015, due to the increase of forestry, the decrease of farmland and grassland, and the expanding of urban area, the streamflow is increased. Compared to the situation in 1990, as shown in Fig. 8, the streamflow in 2015 is decreased by $0.4 \%$ when forestry area is increased by $0.59 \%$, farmland decreased by $0.44 \%$, and grassland decreased by $0.44 \%$. Meanwhile, as the studied area is dominated by forestry, the slight changes of the forestry area will not show obvious streamflow changes. Accordingly, the main driver

Table 4 Model performance statistics of the simulated and measured streamflow at the two gauging stations

\begin{tabular}{|c|c|c|c|c|c|c|c|c|c|}
\hline \multirow[t]{2}{*}{ Station } & \multicolumn{3}{|c|}{ Calibration period } & \multicolumn{3}{|c|}{ Validation period } & \multicolumn{3}{|c|}{ CMADS validation period } \\
\hline & Time & NSE & $R^{2}$ & Time & NSE & $R^{2}$ & Time & NSE & $R^{2}$ \\
\hline Dagutai & $2002-2007$ & 0.75 & 0.76 & 2008-2012 & 0.73 & 0.77 & 2008-2012 & 0.70 & 0.75 \\
\hline Cangping & $2002-2007$ & 0.71 & 0.71 & 2008-2012 & 0.72 & 0.75 & 2008-2012 & 0.84 & 0.84 \\
\hline
\end{tabular}

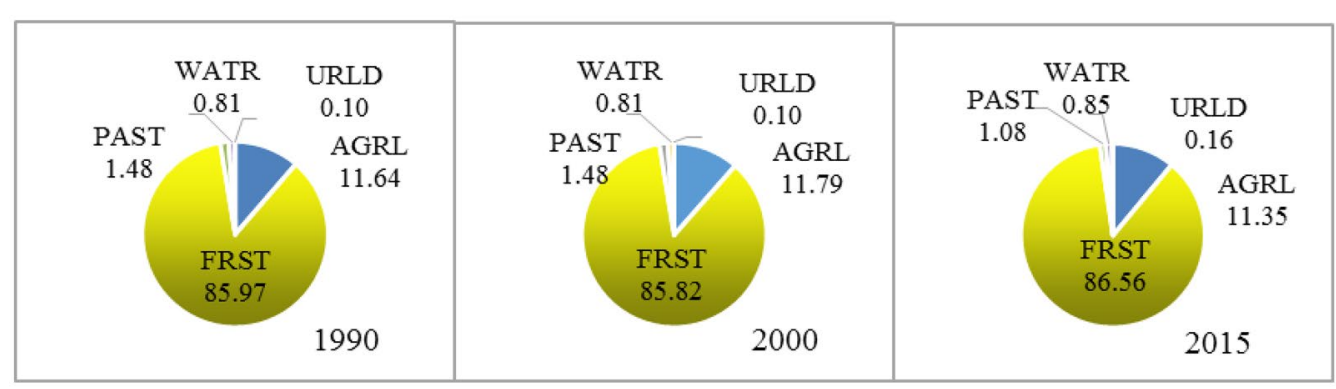

Fig. 7 Percentage of different land use types in year 1990, 2000, and 2015 
Table 5 Transition matrix of land use changes in upper reaches of Zhanghe Reservoir

\begin{tabular}{|c|c|c|c|c|c|c|}
\hline & \multicolumn{6}{|l|}{2015} \\
\hline & AGRL & FRST & PAST & WATR & URLD & Total \\
\hline \multicolumn{7}{|l|}{1990} \\
\hline AGRL & 102 & 128 & 1 & 0 & 1 & 232 \\
\hline FRST & 120 & 1629 & 3 & 10 & 0 & 1762 \\
\hline PAST & 3 & 9 & 18 & 0 & 0 & 30 \\
\hline WATR & 1 & 8 & 0 & 12 & 0 & 21 \\
\hline URLD & 0 & 0 & 0 & 0 & 2 & 2 \\
\hline Total & 226 & 1774 & 22 & 22 & 3 & 2047 \\
\hline
\end{tabular}

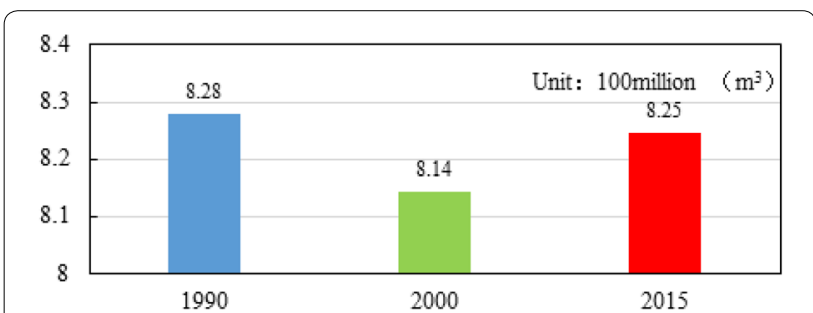

Fig. 8 The multi-year average streamflow generated for three land use conditions in year 1990,2000, and 2015, with other forcing data and parameters remain unchanged

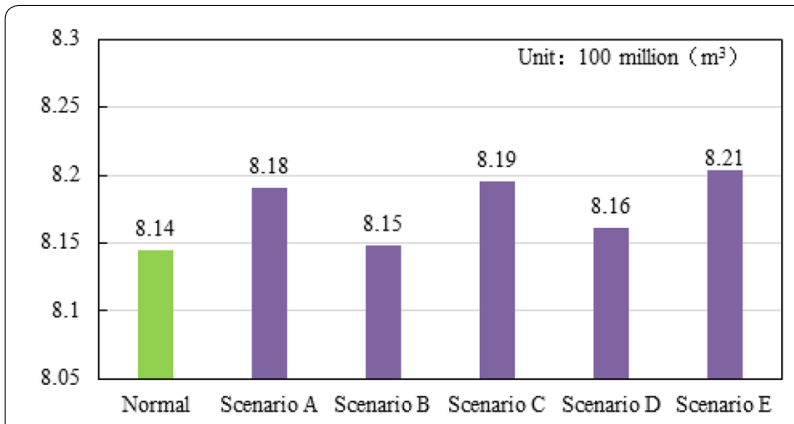

Fig. 9 The multi-year average streamflow generated by normal and designed scenarios

for the streamflow reduction is the reductions of farmland and grassland area, as the increase of forestry may slightly increase the streamflow.

\section{Streamflow responses to different land use scenarios}

The streamflow responses to the five different scenarios, namely Scenarios A, B, C, D, and E, with the unchanged meteorological forcing and other land surface characteristics for the period of 1990-2015, are shown in Fig. 9. The extreme situation in Scenario A shows the streamflow is increased in the situation of completely covered by grassland. When the grassland is increased by $98.5 \%$, the streamflow increased by $0.49 \%$. Compared to the extreme situation in Scenario B, which is fully occupied by forestry, the streamflow is only slightly changed. For Scenario C and D, the decrease of forestry and increase of farmland result in the increase of streamflow by $0.37 \%$. When the urbanization land is increased by $5 \%$, streamflow is increased by $0.86 \%$.

To further display the streamflow responses in extreme situations (i.e., Scenario A and B), Fig. 10 shows their accumulative frequency distribution of monthly streamflow, monthly peak flow, and monthly low flow. Runoff generation in grassland is higher than that in forestry in terms of the monthly average streamflow, as shown in Fig. 10a, which is partly due to the evaporation in forestry is higher than that in grassland, and the forestry is capable to store more water by their large roots. Accordingly, the monthly peak flow in grassland situation is higher than that in forestry, as shown in Fig. 10b. Basically, there are more low flow days when it is completely covered by forestry, compared to those by fully occupied by grassland.

\section{Discussions}

The variability of reservoir inflow of Zhanghe Reservoir in Yangtze River basin is critical to the irrigation district in the lower reaches (the largest irrigation district in Hubei Province) (Sriwongsitanon and Taesombat 2011). To the best of our knowledge, the long-term simulations for the inflow processes for this region have not been effectively implemented. As the drought events were frequently occurred in recent years, it is necessary to have the knowledge of inflow variability and its responses to land use changes in the upper reaches of the reservoir. In particular, the possible low flow responses to land use change are critical to the studied region, as it will further aggravate the drought situation in the future. This study employed the SWAT model to perform this investigation, which is suitable with the obtained simulation accuracy and previous similar topic in other basins (Wang et al. 

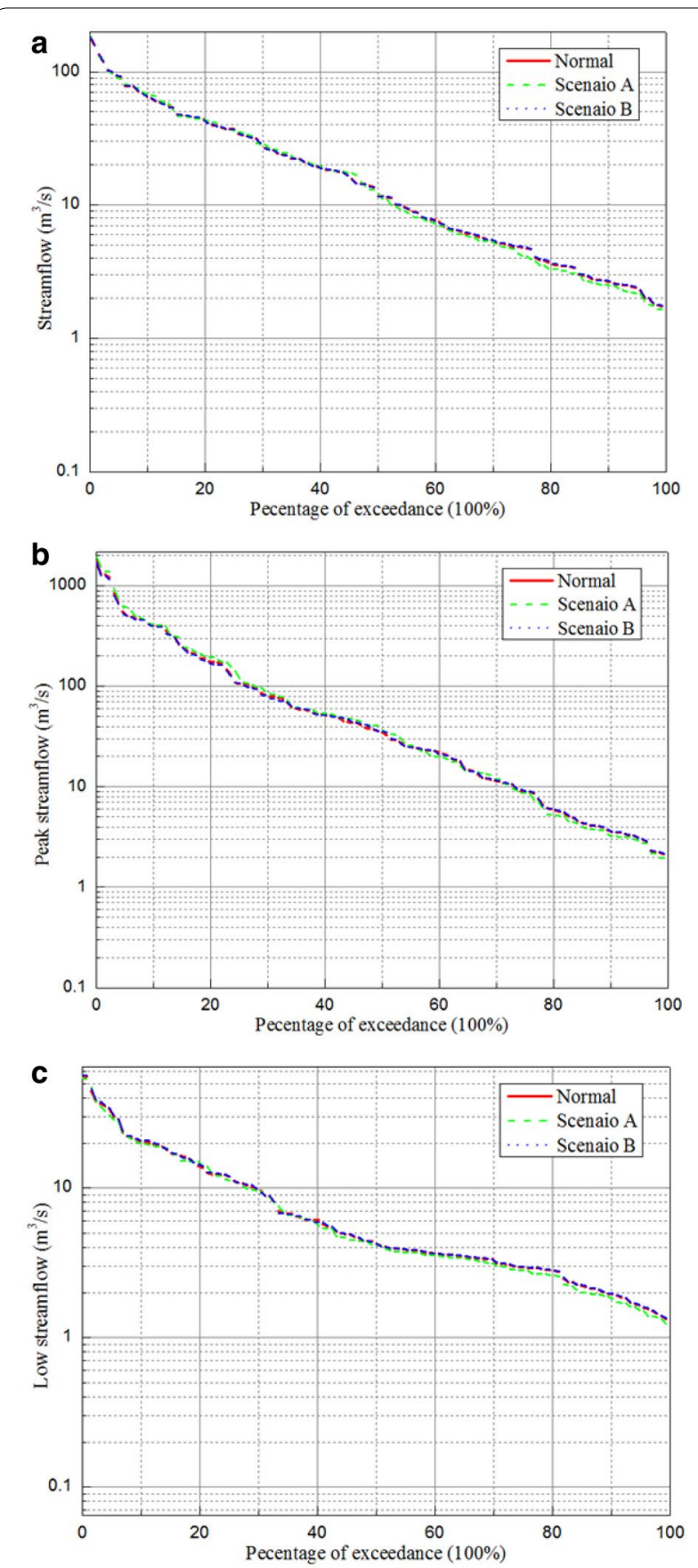

Fig. 10 Cumulative frequency distributions of streamflow simulations for the normal land use cover, scenario A, and scenario B. a Average daily runoff value for each month, $\mathbf{b}$ monthly peak flow, and $\mathbf{c}$ monthly low flow

2014; Anand et al. 2018). Among it, the different meteorological forcing datasets are used for running the model, and we found that the simulations with CMADS dataset show better performance with NSE value 0.84 . This indicates that the reliable meteorological forcing is also very important for the response study. And the more accurate forcing data are desirable for improving the analysis results.

The application of hydrological model (i.e., the SWAT model here) facilitates us to examine the streamflow responses to land use changes, as we can set possible land use change scenarios for the future. Although the past land use change had no significant impacts, the effects of future possible changes remain unfolded. The future land use changes (for example, the forestry is converted to farmland, the farmland is converted to grassland) are possible with the local policy changes. We hold the view that the study provided some valuable information in this regard, which is very useful for designing future sustainable development strategies.

The obtained results on the streamflow responses to land use changes are basically consistent with the reported studies for other studied area. The high and low flow responses to the extreme land cover alterations are consistent with the study of Niu and Sivakumar (2014) for the East River basin in South China. The urbanization increases the runoff generation, which is consistent with the study of Jatin et al. (2018). Certainly, the magnitudes of these changes are different due to the different regional climate, geographical features, and local land surface backgrounds, which also highlight the importance of the regional study for local water resources' management.

In addition, it should be very useful to have the spatial variability of the streamflow variations with probability of exceedance plots. At the current stage, we simulated the streamflow variations at the two hydrological stations and basin outlets. We will report the spatial variability results elsewhere later.

\section{Conclusions}

This study simulates the hydrological processes in the upper reaches of Zhanghe Reservoir in Yangtze River basin and investigates the streamflow responses to land use changes. The SWAT model is employed to perform the hydrological modeling, and the simulations are well validated by two gauging stations in the basin. The historical land use changes are analyzed for both land use area and structure changes. The streamflow (water inflow to the Zhanghe Reservoir) responses to three historical land use situations and different land use scenarios are subsequently investigated based on the well-calibrated model. The following conclusions are drawn based on the relevant simulations and analyses.

1. The sensitive model parameters are obtained for the application of SWAT model in the studied region, including SOL_BD, CH_N2, SURLAG, GW_REVAP, 
and SFTMP. The model shows well performance when the simulations are compared with the streamflow records in two gauging stations (i.e., Dagutai and Cangping) for the period of 2001-2012, with the NSE above 0.7 and $R^{2}$ above 0.71 .

2. The different meteorological forcing datasets are used, and the simulations with CMADS dataset show better performance with NSE value 0.84 .

3. For the historical land use dynamics, the increase of forestry area slightly increases the streamflow response. However, as the land cover in the basin is dominated by forestry, the response is not obvious.

4. For the designed land use scenarios, more runoff is generated when the studied area is fully covered by grassland, compared to the situation completely occupied by forestry. The urbanization increases the water inflow to Zhanghe Reservoir. The extreme events, such as daily peak flow and low flow, show different responses to the different land use scenarios. Daily low flow occurs more when the area dominated by forestry, compared to those by grassland. There is larger daily high flow with more grassland area, in contrast to that with more forestry area.

The irrigation activities in the lower reaches of Zhanghe Reservoir are highly relied on the inflows of the reservoir. The future land use changes (for example, the forestry is converted to farmland, the farmland is converted to grassland) are possible with the local policy changes. The hydrologic simulations and the obtained results on streamflow responses to land use changes are helpful to regional water resources management, especially for facing possible drought events under future changing climate. Meanwhile, the responses are favorable to the sustainable development and environment protection in the upper reaches of the Zhanghe Reservoir in Yangtze River basin.

\section{Acknowledgements}

This research is financially supported by the National Key R\&D Program of China (No. 2017YFC0403201), the Chinese Universities Scientific Fund (2019TC123), and the Innovation of Science and Technology Commission of Shenzhen Municipality Ministry (JCYJ20170413164957461).

\section{Authors' contributions}

Conceptualization, JN; Data curation, YC, PL and LS; Investigation, YC and YS; Methodology, JN; Supervision, JN; Writing —original draft, YC and QL; Writing —review and editing, JN, QL, SL and QL. All authors read and approved the final manuscript.

\section{Funding}

National Key R\&D Program of China (No. 2017YFC0403201);

Chinese Universities Scientific Fund (2019TC123);

Innovation of Science and Technology Commission of Shenzhen Municipality Ministry (JCYJ20170413164957461).

\section{Availability of data and materials}

The data supporting our analyses can be accessed publicly from the link provided in the paper, and the simulation data are available from the corresponding author on reasonable request.

\section{Competing interests}

The authors declare that they have no competing interests.

\section{Author details \\ ${ }^{1}$ Center for Agricultural Water Research in China, China Agricultural University, Beijing 100083, China. ${ }^{2}$ Wuwei Experimental Station for Efficient Water Use in Agriculture, Ministry of Agriculture and Rural Affairs, Wuwei 733000, China. ${ }^{3}$ Shenzhen Institute of Advanced Technology, Chinese Academy of Sciences, Shenzhen 518055, China. ${ }^{4}$ Hubei Zhanghe Project Administration Bureau, Jingmen 448156, China.}

Received: 25 October 2019 Accepted: 28 April 2020

Published online: 06 May 2020

\section{References}

Abbaspour KC, Vejdani M, Haghighat S (2007) SWAT-CUP calibration and uncertainty programs for SWAT. In: Modsim international congress on modelling and simulation: land, water and environmental management: integrated systems for sustainability, Christchurch, New Zealand

Anand J, Gosain AK, Khosa R (2018a) Prediction of land use changes based on land change modeler and attribution of changes in the water balance of ganga basin to land use change using the SWAT model. Sci Total Enviro. 644:503-519

Anand J, Gosain AK, Khosa R (2018b) Prediction of land use changes based on land change modeler and attribution of changes in the water balance of Ganga basin to land use change using the SWAT model. Sci Total Environ 644:503-519

Arnold JG, Srinivasan R, Muttiah RS, Williams JR (1998) Large area hydrologic modeling and assessment part I: model development. J Am Water Resour Assoc 34:73-89

Bonell M, Purandara BK, Venkatesh B, Krishnaswamy J, Acharya HAK, Singh UV, Jayakumar R, Chappell N (2010) The impact of forest use and reforestation on soil hydraulic conductivity in the Western Ghats of India: implications for surface and sub-surface hydrology. J Hydrol 391:47-62

Bouraoui F, Benabdallah S, Jrad A, Bidoglio G (2005) Application of the SWAT model on the Medjerda river basin (Tunisia). Phys Chem Earth 30:497-507

Bradshaw CJA, Sodhi NS, Peh KSH, Brook BW (2007) Global evidence that deforestation amplifies flood risk and severity in the developing world. Global Chang Biol. 13:2379-2395

Bruijnzeel LA (2004) Hydrological functions of tropical forests: not seeing the soil for the trees? Agr Ecosyst Environ 104:185-228. https://doi. org/10.1016/j.agee.01.015

Dechmi F, Skhiri A (2013) Evaluation of best management practices under intensive irrigation using SWAT model. Agric Water Manage. 123:55-64

Fang CH (2004) Study on flood staging and operation of Zhanghe reservoir. Wuhan University, Wuhan

Ficklin DL, Luo Y, Stewart IT, Maurer EP (2012) Development and application of a Hydroclimatological stream temperature model within SWAT. Water Resour 48:1

Gashaw T, Tulu T, Argaw M, Worqlul AW (2018) Modeling the hydrological impacts of land use/land cover changes in the Andassa watershed, Blue NileBasin. Ethiopia. Sci Total Environ. 619-620:1394-1408

Gikas GD, Yiannakopoulou T, Tsihrintzis VA (2006) Modeling of non-point source pollution in a Mediterranean drainage basin. Environ Model Assess 11:219-233

Govender M, Everson CS (2005) Modelling streamflow from two small South African experimental catchments using the SWAT model. Hydrol Process Int J 19(3):683-692

Guo H, Hu Q, Jiang T (2008) Annual and seasonal streamflow responses to climate and land-cover changes in the Poyang Lake basin, China. J Hydrol. 355:106-122

Gutman G, Janetos AC, Justice CO, Moran EF, Mustard JF, Rindfuss RR, Skole D, Turner BL, Cochrane MA (2004) Land change science: observing 
monitoring and understanding trajectories of change on the earth's surface. Springer, Berlin

Han DD (2018) Runoff simulation of Xilin River driven by multi-source data and impact of land cover change on runoff. Inner Mongolia Agricultural University, Inner Mongolia

Hao ZC, Su ZK (2015) Effects of land use change on runoff in typical regions of Haihe river basin. Adv Water Sci 26:491-499

Hernandez M, Miller SN, Goodrich DC, Goff BF, Kepner WG, Edmonds CM, Jones B (2000) Modeling Runoff response to land cover and rainfall spatial variability in Semi-Arid watersheds. Environ Monit Assess. 64:285-298

$\mathrm{Li} \mathrm{HZ} \mathrm{(2007)} \mathrm{Research} \mathrm{on} \mathrm{the} \mathrm{influence} \mathrm{of} \mathrm{land} \mathrm{use/cover} \mathrm{change} \mathrm{on} \mathrm{hydro-}$ logical factors based on SWAT model. Hebei Normal University, Hebei

Li Q, Zhang J, Gong HL (2015) Hydrological simulation and parameter uncertainty analysis using SWAT model based on SUIF-2 algorithm for Guishuihe River Basin. Hydrology. 35:43-48

Li YY, Chang JX, Wang YM, Jin WT, Bai X (2016) Spatial and temporal response of runoff in Weihe River basin to land use change. J Agric Eng 32:232-238

Mehan S, Neupane RP, Kumar S (2017) Coupling of SUFI 2 and SWAT for improving the simulation of streamflow in an agricultural watershed of South Dakota. Hydrol Curr Res 8:3

Meng XY, Yu DL, Liu ZH (2015) Energy balance-based Swat Model To Simulate The Mountain Snowmelt And Runoff-Taking The Application In Juntanghu Watershed (China) as an example. J Mt Sci. 12:368-381

Nash JE, Sutcliffe JV (1970) River flow forecasting through conceptual model, Part 1:a discussion of Principe. J Hydrol 10:282-290

Neitsch SL, Arnold JG, Kiniry JR, Williams JR, King KW (2002) Soil and Water Assessment Tool Theoretical Documentation Version. Agric Res Serv 2005:476

Nicks AD (1974) Stochastic generation of the occurrence, pattern and location of maximum amount of daily rainfall. Proc Symp Stat Hydrol 1974:154

Niu J, Sivakumar B (2014) Study of runoff response to land use change in the East River basin in South China. Stoch Env Res Risk A. 28:857-865

Park JY, Park MJ, Joh HK, Shin HJ, Kwon HJ, Srinivasan R, Kim SJ (2011) Assessment of MIROC3. 2 HiRes climate and CLUE-s land use change impacts on watershed hydrology using SWAT. Trans ASABE. 54(5):1713-1724
Serpa D, Nunes JP, Santos J, Sampaio E, Jacinto R, Veiga S, Lima JC, Moreira M, Cortereal J, Keizer JJ, Abrantes N (2015) Impacts of climate and land use changes on the hydrological and erosion processes of two contrasting Mediterranean catchments. Sci Total Environ 538:64-77

Sriwongsitanon N, Taesombat W (2011) Effects of land cover on runoff coefficient. J Hydrol 410:226-238

Wang R, Kalin L, Kuang W, Tian H (2014) Individual and combined effects of land use/cover and climate change on Wolf Bay watershed streamflow in southern Alabama. Hydrol Process 28:5530-5546. https://doi. org/10.1002/hyp.10057

Wei D, Liu ZY, Li XB (2012) Application of SWAT model and sufi-2 algorithm in runoff simulation of the upper reaches of the Tuwei river. Agric Res Arid Areas 2012:30

Williams JR (1969) Flood routing with variable travel time or variable storage coefficients. T Asabe 12:100-103

Xu ZX, Cheng L (2010) Progress on studies and applications of the distributed hydrological models. J Hydraul Eng 41:1009-1017

Yan B, Fang NF, Zhang PC, Shi ZH (2013) Impacts of land use change on watershed streamflow and sediment yield: an assessment using hydrologic modelling and partial least squares regression. J Hydrol 484:26-37

Yang CW, Lin ST (1997) Flood forecasting and control of Zhanghe reservoir. Hydrology 6:62-64

Zhang YY, Xia J, Yu JJ, Randall M, Zhang YC, Zhao TT, Pan XY, Zhai XY, Shao QX (2018) Simulation and assessment of urbanization impacts on runoff metrics: insights from landuse changes. J Hydrol 560:247-258

\section{Publisher's Note}

Springer Nature remains neutral with regard to jurisdictional claims in published maps and institutional affiliations.

\section{Submit your manuscript to a SpringerOpen ${ }^{\circ}$ journal and benefit from:}

- Convenient online submission

- Rigorous peer review

- Open access: articles freely available online

- High visibility within the field

- Retaining the copyright to your article

Submit your next manuscript at $\boldsymbol{\nabla}$ springeropen.com 